AB0554

\section{SLEEP QUALITY IN PATIENTS WITH PSORIATIC} ARTHRITIS

P. Benzin ${ }^{1}$, Z. R. Stisen ${ }^{1}$, M. Skougaard ${ }^{1}$, T. Schjødt Jørgensen ${ }^{1}$, R. L. Hansen ${ }^{1}$, L. M. Perez-Chada ${ }^{2}$, M. Mogensen ${ }^{3}$, J. F. Merola ${ }^{2}$, L. E. Kristensen ${ }^{1} .{ }^{1}$ Parker Institute, Clinical Research Unit, Frederiksberg, Denmark; ${ }^{2}$ Brigham And Women's Hospital, Department of Dermatology and Department of Medicine, Division of Rheumatology, Boston, United States of America; ${ }^{3}$ Bispebjerg and Frederiksberg Hospital, Department of Dermatology, København, Denmark

Background: Psoriatic arthritis (PsA) is a chronic immune-mediated inflammatory disease. It has a heterogeneous clinical presentation with main features being joint swelling and pain, skin and nail psoriasis, enthesitis, and dactylitis. Self-reported outcomes such as quality of sleep and fatigue are often neglected topics although having great impact on patients' everyday lives.

Objectives: The primary objective was to analyze the prevalence of PsA patients suffering from poor quality of sleep, defined by Pittsburgh Sleep Quality Index (PSQI) score $\geq 5$, and to study the association between being a good or poor sleeper and clinical- and patient-reported outcomes.

Secondary, the effects on outcomes after initiation of treatment.

Methods: Patient characteristics, disease activity and self-reported outcomes were obtained from the PIPA cohort. To evaluate the primary objective, a cross-sectional analysis was conducted including PSQI score at baseline and corresponding data. Patients were divided into two groups, defined as good or poor sleepers (Table 1).

Data from initiation of treatment (baseline) and 4 months follow-up were included when assessing the effect of treatment. Transition of good and poor sleepers from baseline to 4 months follow-up was depicted by a chi-squared test.

A crosstab analysis was performed with baseline PSQI and whether they had widespread pain to investigate a possible link, additionally a Mann-Whitney $\mathrm{U}$ test.

Results: From January 2018-November 2020 a total of 109 patients were included. The prevalence of PsA patients suffering from poor quality of sleep at baseline were $66.1 \%$ whereas the remaining $33.9 \%$ were deemed good sleepers. There was no statistically significant difference in patient demographics when comparing good and poor sleepers at baseline. There was a statistically significant difference in patient-reported outcomes such as Visual Analogue Scale (VAS) pain, VAS global, Health Assessment Questionnaire (HAQ) score and Disease Activity Score (DAS28-CRP), with poor sleepers scoring higher.

57 patients had complete data at 4 months follow-up. At baseline $71.9 \%$ of them were classified as poor sleepers (Figure 1). A chi-squared test presented the transition at 4 months follow-up. $47.4 \%$ of the patients were now classified as poor sleepers.

While 27 poor sleepers became good sleepers, 13 good sleepers became poor sleepers, with data being statistically significant ( $p$ 0.001).

The crosstab analysis exposed 75 patients without widespread pain (mean $7.13 \pm 3.79$ ) and 31 patients with widespread pain (mean 9.52 \pm 4.93 ).

Baseline PSQI and whether the patients had widespread pain was statistically significant ( 0.018 ).

Conclusion: Overall, PsA patients with poor quality of sleep have higher levels in terms of self-reported pain and disease activity.

The amount of good sleepers after 4 months increased, but there was a negative transition of patients going from good to poor sleepers. This could indicate that more factors are important for quality of sleep, e.g. sociopsychological aspects like anxiety, depression, ability to work.

Table 1. Patient characteristics

\begin{tabular}{|c|c|c|c|c|c|c|}
\hline & \multirow[t]{2}{*}{$\begin{array}{c}\text { Total } \\
n=109\end{array}$} & \multicolumn{2}{|c|}{$\begin{array}{c}\text { Good sleepers } \\
\text { PSQI } \leq 5 \\
n=37\end{array}$} & \multicolumn{2}{|l|}{$\begin{array}{c}\text { Poor sleepers } \\
\text { PSQI > } 5 \\
n=72\end{array}$} & \multirow[b]{2}{*}{$\mathrm{p}$} \\
\hline & & & $n$ & & $\mathrm{n}$ & \\
\hline Female, n (\%) & 65 (59.4\%) & 19 (51.4\%) & 37 & 46 (63.9\%) & 72 & 0.206 \\
\hline Age, yrs & $53.9(45.4-62.25)$ & $60.4(45.5-65.2)$ & 37 & $51.5(44.7-59.95)$ & 72 & 0.144 \\
\hline $\begin{array}{l}\text { Disease duration, } \\
\text { yrs }\end{array}$ & $3.86(1.0-11.0)$ & $4.5(1.04-11.06)$ & 34 & $2.91(1.0-10.75)$ & 68 & 0.352 \\
\hline csDMARD, n (\%) & $71(65.1 \%)$ & $26(70.2 \%)$ & 37 & 45 (62.5\%) & 72 & 0.420 \\
\hline bDMARD, n (\%) & $70(64.2 \%)$ & $24(64.8 \%)$ & 37 & 46 (63.9\%) & 72 & 0.920 \\
\hline $\begin{array}{l}\text { Patient pain } \\
\text { assessment }\end{array}$ & $50.0(21.0-74.5)$ & $27.0(9.0-60.5)$ & 37 & $63.5(32.25-78.0)$ & 72 & $<0.001$ \\
\hline \multicolumn{7}{|l|}{$0-100 \mathrm{~mm}$ VAS } \\
\hline $\begin{array}{l}\text { Patient global } \\
\text { assessment }\end{array}$ & $61.0(27.5-78.5)$ & $35.0(17.5-59.0)$ & 37 & $69.5(50.0-85.75)$ & 72 & $<0.001$ \\
\hline \multicolumn{7}{|l|}{$0-100 \mathrm{~mm}$ VAS } \\
\hline PsAID fatigue & $6.0(3.0-8.0)$ & $4.0(2.5-7.0)$ & 37 & $6.5(4.0-8.0)$ & 72 & 0.488 \\
\hline HAQ score, 0-3 & $0.75(0.38-1.25)$ & $0.38(0.25-0.81)$ & 37 & $0.88(0.63-1.38)$ & 72 & $<0.001$ \\
\hline PASI & $1.7(0.0-9.75)$ & $2.0(0.0-7.3)$ & 35 & $1.2(0.0-11.5)$ & 65 & 0.940 \\
\hline DAS28-CRP & $3.77(3.02-4.58)$ & $3.44(2.65-3.94)$ & 37 & $4.07(3.28-4.93)$ & 72 & 0.001 \\
\hline
\end{tabular}

Figure 1. Quality of sleep
Baseline

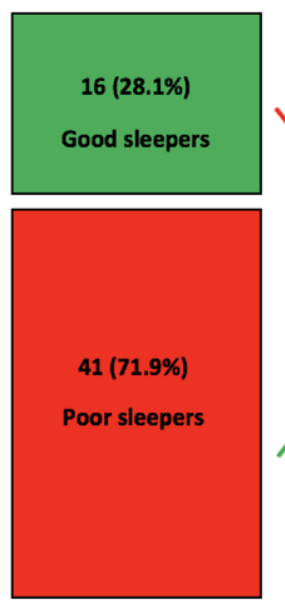

4 months follow-up

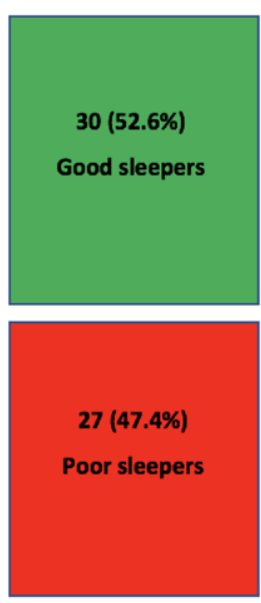

Disclosure of Interests: Peter Benzin: None declared., Zara Rebecca Stisen: None declared., Marie Skougaard: None declared., Tanja Schjødt Jørgensen Speakers bureau: Received consulting fees and/or speaking fees from AbbVie, Pfizer, Roche, Novartis, UCB, Biogen and Eli Lilly, Consultant of: Received consulting fees and/or speaking fees from AbbVie, Pfizer, Roche, Novartis, UCB, Biogen and Eli Lilly, Rebekka L. Hansen: None declared., Lourdes M. PerezChada: None declared., Mette Mogensen: None declared., Joseph F. Merola Consultant of: Consultant and/or investigator for Merck, Bristol-Myers Squibb, AbbVie, Dermavant, Eli Lilly, Novartis, Janssen, UCB, Sanofi, Regeneron, Arena, Sun Pharma, Biogen, Pfizer, EMD Sorono, Avotres and Leo Pharma., Lars Erik Kristensen Speakers bureau: Received fees for speaking and consultancy from Pfizer, AbbVie, Amgen, UCB, Gilead, Biogen, BMS, MSD, Novartis, Eli Lilly, and Janssen pharmaceuticals., Consultant of: Received fees for speaking and consultancy from Pfizer, AbbVie, Amgen, UCB, Gilead, Biogen, BMS, MSD, Novartis, Eli Lilly, and Janssen pharmaceuticals.

DOI: 10.1136/annrheumdis-2021-eular.2294

\section{AB0555 IMPACT OF ADALIMUMAB VERSUS NON-BIOLOGIC THERAPY ON CLINICAL AND PATIENT-REPORTED OUTCOMES IN PSORIATIC ARTHRITIS OVER 24 MONTHS - RESULTS OF THE COMPLETE-PSA CANADIAN OBSERVATIONAL STUDY}

M. Khraishi ${ }^{1}$, S. Silverberg ${ }^{2}$, Y. Setty ${ }^{3}$, M. C. Laliberté ${ }^{4}$, L. Bessette ${ }^{5} .{ }^{1}$ Memorial University of Newfoundland, Memorial University of Newfoundland, St. John's, Canada; ${ }^{2}$ Etobicoke General Hospital, Etobicoke General Hospital, Toronto, Canada; ${ }^{3}$ Grey Bruce Health Services, Grey Bruce Health Services, Owen Sound, Canada; ${ }^{4} \mathrm{AbbVie}$ Corporation, Montreal, AbbVie Corporation, Montreal, Montreal, Canada; ${ }^{5}$ Laval University, Centre Hospitalier de I'Université Laval, Laval University, Centre Hospitalier de l'Université Laval, Quebec City, Canada

Background: COMPLETE-PSA was a Canadian observational study of biologic-naïve adults with active psoriatic arthritis (PsA) treated with adalimumab (ADA) or conventional systemic disease-modifying anti-rheumatic drugs (csDMARDs) after switch from a previous conventional therapy.

Objectives: To compare the impact of ADA vs csDMARDs on clinical and patient-reported outcomes due to PsA over 24 months.

Methods: Eligible patients were biologic naïve adults with active PsA who required change in their treatment due to inadequate response or non-tolerance, as per treating physician judgement. Patients were enrolled between July/2011 and December/2017 and followed for a maximum 24 months. Treatment was as per routine care. Outcome measures included tender/swollen joint count (TJC/ $\mathrm{SJC}$ ), morning stiffness ( $\mathrm{min} /$ day), patient's global assessment of disease activity (PtGA) and pain (both $100 \mathrm{~mm}$ VAS), quality of life (DLQI), and functional disability (HAQ-DI). Outcome changes over time were evaluated using multivariable models adjusting for baseline measures. Achievement of modified minimal disease activity [mMDA, $5 / 7$ of: TJC and SJC $\leq 1$ each, psoriasis BSA $\leq 3 \%$, pain $\leq 15$ (VAS, mm), PtGA $\leq 20, \mathrm{HAQ}-\mathrm{DI} \leq 0.5$, and no enthesitis], and presence of enthesitis and dactylitis, were assessed descriptively. Analyses were conducted in the intent-to-treat population.

Results: A total of 277 ADA and 148 csDMARD-treated patients were included in the analysis. At baseline, $61.7 \%$ of ADA and $81.1 \%$ of csDMARD patients reported concomitant methotrexate. Compared to the csDMARD group, ADA-treated 